\title{
Community Characteristics Associated with Premature Mortality in the Appalachian Region
}

\author{
Alexander V Sergeev* and Margaret A Sabec \\ Department of Social and Public Health, Ohio University, USA
}

*Corresponding author: Alexander V Sergeev, Associate Professor, Department of Social and Public Health, Ohio

University, Grover Center W343, USA

\section{ARTICLE INFO}

Received: February 25, 2021

Published: 絊 March 03, 2021

Citation: Alexander V Sergeev, Margaret A Sabec . Community Characteristics Associated with Premature Mortality in the Appalachian Region. Biomed J Sci \& Tech Res 34(2)-2021. BJSTR. MS.ID.005537.

Keywords: Premature Mortality; Disparities; Appalachian Region

\section{ABSTRACT}

Background: A key component of population health status is premature mortality, defined as a death occurring before the age of 75 years. Of particular concern is premature mortality among vulnerable populations of Appalachia. However, it remains unclear what specific community characteristics are the leading predictors of premature mortality in the Appalachian population to be considered when developing high-priority interventions to improve premature mortality.

Objective: We hypothesized that a limited number of community characteristics would account for most of premature deaths in the Appalachian population. The objective of our study was to identify these essential community characteristics.

Methods: County Health Rankings and Roadmaps data were used to investigate premature mortality, as measured by the number of years of potential life lost (YPLL) before age 75 years per 100,000 population (age-adjusted), and associated community characteristics in the 13 Appalachian states. Counties' rurality status was defined using the United States Departments of Agriculture Economic Research Service's (USDA ERS) Rural-Urban Continuum Codes (RUCC). Descriptive and inferential statistical analyses, including multiple regression, were conducted using SAS and SPSS. A conventional Type I error (alpha) level of $0.05(\mathrm{p}<0.05)$ was used for all analyses.

Results: Premature mortality rates, as measured by the number of years of potential life lost (YPLL) before age 75 years, in the 420 Appalachian counties were statistically significantly higher than in their counterparts - the 679 non-Appalachian counties of the 13 Appalachian states: 9,299.7 vs. 8,425.4 per 100,000 ( $\mathrm{p}<0.001)$. Within the Appalachian counties, premature mortality rates were statistically significantly higher in rural areas than in urban areas: YPLL 10,010.9 vs. 8,546.6 per 100,000 ( $<<0.001)$. Multivariable analysis identified key factors predicting premature mortality in the Appalachian population that can be grouped into three major categories: health behavior, health care, and social environment factors.

Conclusions: Premature mortality in rural Appalachian counties is statistically significantly higher than in urban Appalachian counties. The key predictors of premature mortality in the Appalachian Region can be grouped into three major categories: health behavior; health care; and social environment factors. This study furthers the body of knowledge necessary to develop targeted interventions to improve premature mortality in the Appalachian Region.

\section{Introduction}

A key component of population health status is premature mortality, defined as a death occurring before the age of 75 years $[1,2]$. Premature mortality is a major public health problem both in the United States and worldwide, and it is exacerbated by socioeconomic disparities [3-5]. Stretching along the Appalachian Mountains and covering the area over 200,000 square miles, the 
Appalachian Region is composed of 420 counties across 13 states - parts of Alabama, Georgia, Kentucky, Maryland, Mississippi, New York, North Carolina, Ohio, Pennsylvania, South Carolina, Tennessee, and Virginia, and the entire state of West Virginia and has a population of 25 million people [6]. The Appalachian Region's population is vulnerable to socio-economic disparities and associated public health issues [7]. It has income level below the U.S. average and unemployment rates above the U.S. average rates, and only about $25 \%$ of the Appalachian adults hold a bachelor's degree, compared to nearly 33\% nationwide [8]. Of particular concern is premature mortality among the vulnerable population of the Appalachian Region. However, it remains unclear what specific community characteristics are the leading predictors of premature mortality in the Appalachian population to be considered when developing high-priority interventions to improve premature mortality. We hypothesized that a limited number of community characteristics would account for most of premature deaths in the Appalachian population. The objective of our study was to identify these essential community characteristics.

\section{Methods}

\section{Study Population}

Table 1: Categories and sub-categories of the County Health Rankings and Roadmaps measures.

\begin{tabular}{|c|c|}
\hline Categories & Sub-Categories \\
\hline \multirow{2}{*}{ Health Outcomes } & Length of Life \\
\hline Health Factors & Quality of Life \\
\hline & Health Behaviors: \\
\hline & Tobacco Use \\
\hline & Diet and Exercise \\
\hline & Alcohol and Drug Use \\
\hline & Sexual Activity \\
\hline & Clinical Care: \\
\hline & Access to Care \\
\hline & Quality of Care \\
\hline & Social and Economic Factors: \\
\hline & Education \\
\hline & Employment \\
\hline & Income \\
\hline & Family and Social Support \\
\hline & Community Safety \\
\hline & Physical Environment: \\
\hline & Environmental Quality \\
\hline & Housing and Transit \\
\hline & Demographics \\
\hline
\end{tabular}

We conducted a population-based study of premature mortality and associated community characteristics in the 13 Appalachian states: Alabama, Georgia, Kentucky, Maryland, Mississippi, New York, North Carolina, Ohio, Pennsylvania, South Carolina, Tennessee, and Virginia, and West Virginia, using the County Health Rankings and Roadmaps (CHRR) data [9,10]. CHRR databases provide county-level data on over 60 measures both on health outcomes and health factors - grouped into several focus areas (Table 1). Counties' rurality status was classified using the US Department of Agriculture (USDA) Economic Research Service's (ERS) county Rural-Urban Continuum Code system (RUCC). The continuum of the established RUCC codes ranges from 1(counties in metro areas of $>1$ million population) to 9 (completely rural or $<2,500$ urban population, not adjacent to a metro area) [11]. We classified nonmetropolitan counties with population less than 20,000 as rural (RUCC codes 6-9) and other counties (RUCC codes 1-5) as urban. Of the total of 420 Appalachian counties (total population: 25,482,969), 217 were classified as rural (population: 4,942,752) and 203 were classified as urban (population: 20,540,217).

\section{Statistical Analysis}

The primary outcome of interest was premature mortality, as measured by the number of years of potential life lost (YPLL) before age 75 years per 100,000 population (age-adjusted). Both bivariate and multivariate inferential statistical analyses were conducted. Bivariate analyses for continuous variables were conducted using t-test. Multivariable analysis was conducted using multiple regression. For statistical significance evaluation, a conventional Type I error (alpha) level of $0.05(\mathrm{p}<0.05)$ was used for all analyses. All statistical analyses were performed using SAS ver. 9.4 (SAS Institute Inc., Cary, NC) and SPSS (The IBM SPSS) statistical software. The study was approved by the Ohio University Institutional Review Board (IRB).

\section{Results}

\section{Bivariate Analysis}

Within the 13 states containing Appalachian counties, ageadjusted premature mortality rates (YPLL) in the 420 Appalachian counties were statistically significantly higher than in their counterparts - the 679 non-Appalachian counties of the 13 Appalachian states: 9,299.7 YPLL per 100,000 vs. 8,425.4 YPLL per 100,000 $(\mathrm{p}<0.001)$. Within the 420 Appalachian counties, premature mortality rates (YPLL) were statistically significantly higher in rural counties than in urban counties: 10,010.9 YPLL per 100,000 vs. $8,546.6$ YPLL per $100,000(\mathrm{p}<0.001)$. Bivariate analysis comparing rural and urban Appalachian counties indicated that rural Appalachian counties have a statistically significantly higher prevalence of unhealthy behaviors and their proxy measures (such as smoking, obesity, physical inactivity, lack of access to exercise opportunities) , lower access to health care and lower utilization of healthcare services (a statistically significantly higher percentage uninsured, lower average number of primary care physicians per 100,000 population, lower percentage of diabetes monitoring, and lower percentage of mammography screening), statistically significantly higher unemployment, lower percentage of adults with some post-secondary education, and higher percentage of children living in poverty (Table 2). 
Table 2: Comparison of rural and urban Appalachian counties by health factors.

\begin{tabular}{|c|c|c|c|}
\hline & $\begin{array}{l}\text { Rural Appalachian } \\
\text { Counties ( }=217)\end{array}$ & $\begin{array}{l}\text { Urban Appalachian } \\
\text { Counties }(n=203)\end{array}$ & P-Value \\
\hline $\begin{array}{l}\text { Adult smoking (percentage of adults that report currently smoking), mean } \\
\text { percent (SD) }\end{array}$ & $22.2(3.8)$ & $20.2(2.9)$ & $<0.001$ \\
\hline $\begin{array}{l}\text { Adult obesity (percentage of adults that report BMI >30), mean percent } \\
\text { (SD) }\end{array}$ & $33.1(3.8)$ & $31.9(3.5)$ & $<0.001$ \\
\hline $\begin{array}{l}\text { Physical inactivity (percentage of adults that report no leisure-time } \\
\text { physical activity), mean percent (SD) }\end{array}$ & $32.2(4.5)$ & $29.6(4.7)$ & $<0.001$ \\
\hline $\begin{array}{l}\text { Access to exercise opportunities (percentage of the population with access } \\
\text { to places for physical activity), mean percent (SD) }\end{array}$ & $53.7(24.4)$ & $64.8(18.7)$ & $<0.001$ \\
\hline $\begin{array}{l}\text { Uninsured (percentage of people under age } 65 \text { who without insurance), } \\
\text { mean percent (SD) }\end{array}$ & $18.4(3.5)$ & $16.0(3.6)$ & $<0.001$ \\
\hline $\begin{array}{l}\text { Primary care physicians (PCP) rate (average number of PCP per 100,000 } \\
\text { population), mean (SD) }\end{array}$ & $45.5(23.1)$ & $59.1(40.5)$ & $<0.001$ \\
\hline $\begin{array}{l}\text { Diabetes monitoring (percentage of diabetic Medicare enrollees ages 65- } \\
75 \text { that receive HbA1c monitoring), mean percent (SD) }\end{array}$ & $85.2(4.7)$ & $86.2(3.0)$ & 0.01 \\
\hline $\begin{array}{l}\text { Mammography screening (percentage of Medicare female enrollees having } \\
\text { at least one mammogram in two years), mean percent (SD) }\end{array}$ & $57.2(8.1)$ & $61.6(6.0)$ & $<0.001$ \\
\hline Education: high school graduation rate (percentage), mean percent (SD) & $86.3(7.4)$ & $84.9(6.6)$ & 0.043 \\
\hline $\begin{array}{l}\text { Education: some college (percentage of adults with some post-secondary } \\
\text { education), mean percent (SD) }\end{array}$ & $45.8(7.4)$ & $54.0(9.5)$ & $<0.001$ \\
\hline $\begin{array}{l}\text { Unemployment (percentage unemployed and looking for work), mean } \\
\text { percent (SD) }\end{array}$ & $8.1(2.0)$ & $6.7(1.2)$ & $<0.001$ \\
\hline $\begin{array}{l}\text { Children in poverty (percentage of children living in poverty), mean } \\
\text { percent (SD) }\end{array}$ & $30.8(7.3)$ & $24.4(5.7)$ & $<0.001$ \\
\hline
\end{tabular}

\section{Multivariable Analysis}

To identify the key factors predicting age-adjusted premature mortality in the Appalachian Region, we conducted multivariable analysis with multiple linear regression, with the number of YPLL as the dependent (outcome) variable. Results of the multiple linear regression are presented in Table 3. Smoking $(\mathrm{p}<0.001)$, physical inactivity $(\mathrm{p}<0.001)$, unemployment $(\mathrm{p}<0.001)$, and percentage of children living in poverty $(\mathrm{p}<0.001)$ were statistically significantly directly associated with premature mortality: an increase in these factors was associated with an increase in the number of YPLL (Table 3). Mammography screening $(\mathrm{p}=0.019)$ and high school graduation rates $(\mathrm{p}=0.006)$ were statistically significantly inversely associated with premature mortality: an increase in these factors was associated with a decrease in the number of YPLL (Table 3).

Table 3: Predictors of the YPLL in the Appalachian region: results from multiple linear regression.

\begin{tabular}{|c|c|c|c|}
\hline & $\begin{array}{l}\text { Parameter Estimate } \\
\text { Beta }\end{array}$ & Standard Error & P-Value \\
\hline Adult smoking (percentage of adults that report currently smoking) & 108.70 & 32.35 & $<0.001$ \\
\hline $\begin{array}{l}\text { Physical inactivity (percentage of adults that report no leisure-time } \\
\text { physical activity) }\end{array}$ & 123.42 & 20.25 & $<0.001$ \\
\hline Uninsured (percentage of people under age 65 who without insurance) & -46.32 & 22.70 & 0.042 \\
\hline $\begin{array}{c}\text { Mammography screening (percentage of Medicare female enrollees having } \\
\text { at least one mammogram in two years) }\end{array}$ & -27.51 & 11.77 & 0.019 \\
\hline Education: high school graduation rate (percentage) & -30.11 & 10.98 & 0.006 \\
\hline Unemployment (percentage unemployed and looking for work) & 257.51 & 64.12 & $<0.001$ \\
\hline Children in poverty (percentage of children living in poverty) & 81.88 & 17.89 & $<0.001$ \\
\hline
\end{tabular}

\section{Discussion}

Our study found statistically significantly higher premature mortality rates in the Appalachian counties compared to their non-Appalachian counterparts as well as rural-urban disparities in premature mortality in the Appalachian Region. We also identified the key predictors of premature mortality in the Appalachian population which is vulnerable to socio-economic disparities [7]. Rural-urban premature mortality disparities can be attributed to several factors. Firstly, urban areas have better availability of healthcare services, with more healthcare facilities and health providers per capita. We found that the number of PCP per 100,000 residents is higher in urban Appalachian counties than in rural 
ones. Our findings of health services disparities are consistent with findings from other studies that reported rural-urban disparities in mortality [12-14]. Lack of healthcare providers in rural areas and issues with rural hospital closures were reported $[15,16]$. Secondly, limited availability is exacerbated by limited accessibility impeded by transportation barriers in rural areas. We found that rural Appalachian residents are less likely to undergo mammography screening and diabetes monitoring than urban residents. Other studies demonstrated that rural residence is associated with longer travel distances and longer lasting trips to health care resulting in unmet health care needs $[17,18]$.

Thirdly, our results demonstrated a higher prevalence of unhealthy behaviors, such as smoking and physical inactivity, in rural Appalachian counties compared to their urban counterparts. Our findings are consistent with results from other studies that demonstrated higher prevalence of non-smoking, aerobic leisure time physical activity and fruit consumption along with lower prevalence of obesity among the adults residing in urban counties than in non-urban ones [19,20]. Our study identified essential, statistically significant key predictors of premature mortality in the Appalachian Region: smoking, physical inactivity, unemployment and children in poverty (statistically significantly associated with a higher premature mortality) and those which are statistically significantly associated with a lower premature mortality (mammography screening and high school graduation). These key predictors can be grouped into three major categories: health behavior (smoking, physical inactivity), health care utilization (mammography screening), and social environment factors (unemployment, percentage of children in poverty, high school graduation rate). Our study is not free from limitations. Because only county-level data were available, the results cannot be extrapolated directly to the individual level. Nevertheless, the objective of our study was to investigate the big picture of premature mortality in the Appalachian Region and community characteristics associated with disparities in premature mortality in this population.

\section{Conclusions}

Premature mortality in rural Appalachian counties is statistically significantly higher than in urban Appalachian counties. The key predictors of premature mortality in the Appalachian Region can be grouped into three major categories: health behavior; health care; and social environment factors. This study furthers the body of knowledge necessary to develop targeted interventions to improve premature mortality in the Appalachian Region.

\section{References}

1. (2021) America's Health Rankings. Premature Death. Americas Health Rankings org.
2. Lewer D, Jayatunga W, Aldridge RW, Edge C, Marmot M, et al. (2020) Premature mortality attributable to socioeconomic inequality in England between 2003 and 2018: an observational study. Lancet Public Health 5(1): e33-e41.

3. Best AF, Haozous EA, de Gonzalez AB, Chernyavskiy P, Freedman ND, et al. (2018) Premature mortality projections in the USA through 2030: a modelling study. Lancet Public Health 3(8): e374-e384.

4. GBD 2015 Mortality and Causes of Death Collaborators (2016) Global, regional, and national life expectancy, all-cause mortality, and causespecific mortality for 249 causes of death, 1980-2015: a systematic analysis for the Global Burden of Disease Study 2015. Lancet 388(10053): 1459-1544.

5. Ediriweera DS, Karunapema P, Pathmeswaran A, Arnold M (2018) Increase in premature mortality due to non-communicable diseases in Sri Lanka during the first decade of the twenty-first century. BMC Public Health 18(1): 584.

6. (2021) Appalachian Regional Commission. About the Appalachian Region. www.arc.gov/about-the-appalachian-region. Accessed 2 February 2021.

7. McGarvey EL, Leon-Verdin M, Killos LF, Guterbock T, Cohn WF (2011) Health disparities between Appalachian and non-Appalachian counties in Virginia USA. J Community Health 36(3): 348-356.

8. (2020) Population Reference Bureau. The Appalachian Region: A Data Overview From the 2014-2018 American Community Survey. PRB.

9. (2021) County Health Rankings and Roadmaps. Measures and Data Sources.

10. (2021) County Health Rankings and Roadmaps. Premature death (YPLL).

11. (2012) USDA Economic Research Service. Rural Classifications: What is Rural? United States Department of Agriculture Economic Research Service (USDA ERS).

12. Womack LS, Rossen LM, Hirai AH (2020) Urban-rural infant mortality disparities by race and rthnicity and cause of death. Am J Prev Med 58(2): 254-260.

13. Singh GK, Williams SD, Siahpush M, Mulhollen A (2011) Socioeconomic, rural-urban, and racial inequalities in US cancer mortality: Part I-All cancers and lung cancer and Part II-Colorectal, prostate, breast, and cervical cancers. J Cancer Epidemiol 2011: 107497.

14. Singh GK, Siahpush M (2014) Widening rural-urban disparities in life expectancy, U.S., 1969-2009. Am J Prev Med 46(2): e19-e29.

15. Miller D (2011) Health Care Workforce Shortages Critical in Rural America. Council of State Governments.

16. Kaufman BG, Thomas SR, Randolph RK, Perry JR, Thompson KW, et al. (2016) The rising rate of rural hospital closures. J Rural Health 32(1): 35-43.

17. Probst JC, Laditka SB, Wang JY, Johnson AO (2007) Effects of residence and race on burden of travel for care: cross sectional analysis of the 2001 US National Household Travel Survey. BMC Health Serv Res 7: 40.

18. Skinner AC, Slifkin RT (2007) Rural/urban differences in barriers to and burden of care for children with special health care needs. J Rural Health 23(2): 150-157.

19. Matthews KA, Croft JB, Liu Y, Kanny D, Wheaton AG, et al. (2017) Healthrelated behaviors by urban-rural county classification - United States, 2013. MMWR Surveil Summ 66(SS-5): 1-8.

20. Cohen SA, Greaney ML, Sabik NJ (2018) Assessment of dietary patterns, physical activity and obesity from a national survey: Rural-urban health disparities in older adults. PLoS One 13(12): e0208268. 
ISSN: 2574-1241

DOI: 10.26717/BJSTR.2021.34.005537

Alexander V Sergeev. Biomed J Sci \& Tech Res

(C) (P) This work is licensed under Creative

Submission Link: https://biomedres.us/submit-manuscript.php

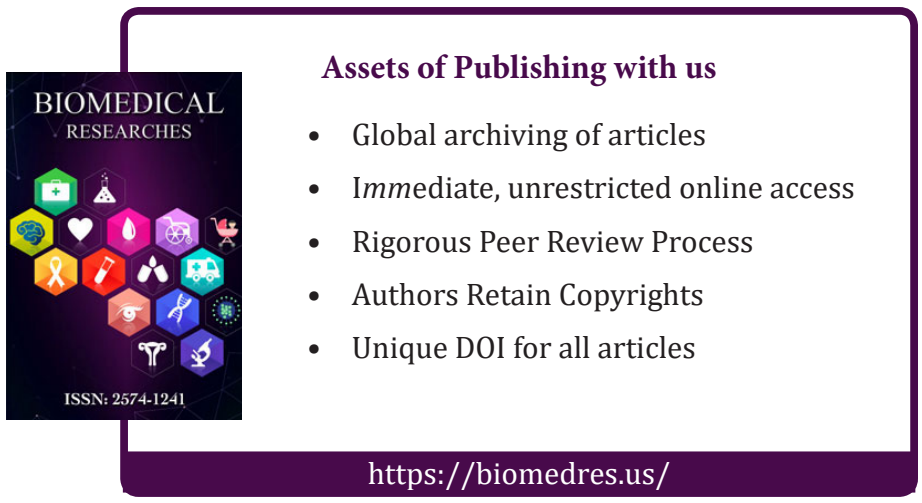

